\title{
Test Analysis on the Dynamic Performance of Frozen Silty Clay
}

\author{
Zheng Bin ${ }^{1}$, Xu Yang ${ }^{2}$, Zheng Shanshan ${ }^{1}$ and Qu Shuying ${ }^{1, *}$ \\ ${ }^{I}$ School of Civil Engineering, Yan Tai University, Yan Tai, China; ${ }^{2}$ City Building Industry Management Office, Fu Shan \\ District, Yan Tai, China
}

\begin{abstract}
Currently, over half of China's trunk railways are located in permafrost regions. But to tackle the railway subgrade disease has always been the difficulty in the railway construction there. The influence that the dynamics performance of frozen silty clay has on permafrost subgrade is an important component in the researches towards permafrost subgrade. In this paper, the dynamics performance of frozen silty clay in permafrost regions is studied based on the indoor dynamic triaxial test at a low temperature, and at the same time, by studying the influence that several factors like cyclic matrix, confining pressure, temperature and frequency have on relevant dynamics parameters, basis can be provided for the transformation and settlement mechanism of permafrost subgrade as well as for the analysis towards the permafrost's influence on vibration response under train load, and it offers much reference value to permafrost subgrade's design.
\end{abstract}

Keyword: Confining pressure, dynamic parameters, dynamic triaxial test, permafrost, stepped loading.

\section{INTRODUCTION}

Frozen soil is a special form of soil which is divided into two types: permafrost and seasonal frozen soil. The former is the kind of soil which is frozen for more than three consecutive years, and generally, the freeze-thaw cycle takes place within several meters of its surface as the season changes. While the latter, seasonal frozen soil, usually refers to the one freezes within only a few meters on the surface, and often melts in summer and freezes in winter. The permafrost occupies about a quarter of the world's land area, and nowadays, over half of the trunk railways in China--one of the countries with large frozen soil areas in the world [1], are constructed in frozen soil regions. With the complete advance of the national infrastructure construction, the railway construction in frozen soil area has been promoted year by year [2]. However, a series of problems associated with that have caused the attention of scholars both at home and abroad.

The Mechanics of Frozen Ground published in 1930 by Н.А. Цытович [3] laid the foundation for permafrost researches. Based on the dynamic triaxial test at a low temperature, $\mathrm{T}$ Chaichanavong [4] did a research on the dynamic property of ice and frozen soil; Li J C [5], based on the dynamic triaxial test at a low temperature, did researches towards the relationship between frozen soil's dynamics parameters and their influencing factors; while Ting $\mathrm{J}$ M [6], together with other colleagues, studied the dynamic strength characteristics of frozen sand on the basis of many document statistics. Moon-Young Kim [7] proved by experiments that the cementing power between soil and ice is much larger than that between soil and water. Zhu Yuanlin and He Ping
[8] did a triaxial creep test on the frozen silt (loess in Lanzhou)'s axial vibration under different confining pressures, and put forward the triaxial creep model when the frozen soil was under vibrating load, meanwhile, they discussed the physical significance and change rules of all the parameters in the model. Xu Xueyan [9, 10], through carrying out large numbers of dynamic triaxial tests at a low temperature, figured out how to determine the frozen soil's stress-strain relationship, parameters and dynamic elastic modulus. Meanwhile, she was the first person in China who figured out the dynamic poisson's ratio of the frozen soil, and provided the numerical values of dynamic elastic modulus, dynamic poisson's ratio, dynamic shear modulus and dynamic damping ratio, and at the same time illustrated the relationship between these parameters and the temperatures as well as vibration frequencies of the frozen soil. Zhao Shuping [11] found that the frozen soil's dynamic elastic modulus increases with increasing frequency or decreasing temperature, and reaches a maximum in the vicinity of the saturated water content, while its dynamic damping ratio decreases with increasing frequency or decreasing temperature, and rises slightly when water content gets higher. Shi Yehui [12] tested the high-temperature permafrost body of Qinghai-Tibet railway under different confining pressures, frequencies, temperatures and moisture contents, and found that its elasticity modulus is mostly influenced by temperature, while fluctuates as the confining pressure changes, and increases with increasing frequency. Zhu Zhanyuan [13-15], together with other people, carried out studies on the dynamic constitutive relation and mechanics parameters of the frozen clay in Beiluhe roadbed of Qinghai Tibet Railway and did researches towards the influence that the permafrost has on subgrade's vibration response, as well as towards the prediction of dynamic settlement caused by the train's long-term running. Based on this, he also discussed the dynamic response characteristics of the permafrost subgrade during the train's running. In order to study the mechanical property of 
the contact surface of frozen soil-concrete, Lv Peng [16] invented a dynamic-load direct shear apparatus that can be operated under low temperature. Based on the common direct shear apparatus, he installed the dynamic loading system and the temperature control system to make it an installation that can carry out dynamic-load direct shear test on the frozen soils under minus temperature, thus measuring the dynamic parameters of the permafrost. Xu Xiangtian [17], together with other people, used the low temperature triaxial apparatus and its control software from the national key laboratory for permafrost engineering to carry out various isobaric tests as well as triaxial shear loading and unloading tests towards the frozen soil sample. From these, $\mathrm{Xu}$ got a clear understanding about the application range of frozen soil's mechanical test method and the influence that the equivalent shear stress has on frozen soil's volume deformation. Based on this, he made a testing program on equal-p of frozen soil and made great contributions to increasing the accuracy of frozen soil's mechanical test as well as exploring its mechanical properties.

As can be seen from the above research findings, currently, there are few studies focusing on the dynamics problems caused by rail traffic load, such as the vibration input mechanism and reaction behavior of permafrost subgrade under the train's high-speed running, the deformation and settlement mechanism of permafrost subgrade under long-term vibration load, as well as the influence that the permafrost has on vibration response, etc. In this paper, based on the indoor dynamic triaxial test at a low temperature, the dynamics performance of frozen silty clay in the Amdo test section, which is located in the GA Loeb Valley, part of the permafrost region of the Qinghai-Tibet Plateau, is studied, and the influence that several factors like temperature, confining pressure, water content and frequency have on its dynamic parameters is also analyzed.

\section{MATERIALS AND METHODOLOGY}

\subsection{Test Instruments and Performance}

The MTS- 810 dynamic triaxial material testing machine is used in this test with a maximum axial load of $100 \mathrm{kN}$. The test instrument is shown in (Fig. 1).

\subsection{Physical Properties of the Sample and Specimen Preparation}

The silty clay along the Qinghai-Tibet railway is used in the test, and its physical parameters are shown in Table $\mathbf{1}$. Based on the Standard for Soil Test Method [18] and Code for Measurement Method of Dynamic Properties Subsoil [19], the reconstituted cylinder specimen, whose standard diameter and height is $61.8 * 125 \mathrm{~mm}$ and average density is $1.8 \mathrm{~g} / \mathrm{cm} 3$, is prepared in this test. Samples are sealed and fixed by copper-formed mold in batches and are stored in the quick-freezing thermotank for over 24 hours. Then sealed by rubber membranes, they are stored for at least 12 hours in the thermotank which is set under controlled temperature in a way to ensure the temperature of the sample meets the requirement. The temperature error in the thermotank is \pm 0.1 ${ }^{\circ} \mathrm{C}$, and the prepared samples are as (Fig. 1) shows.

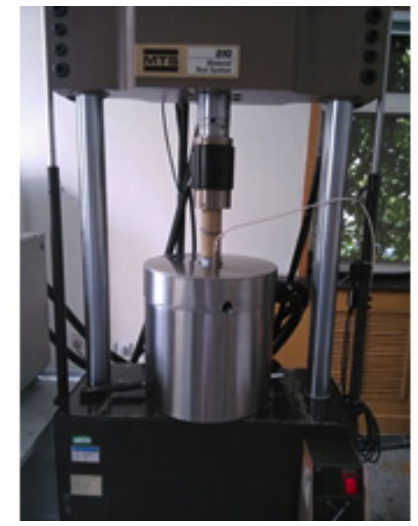

a. MTS-810 material testing machine

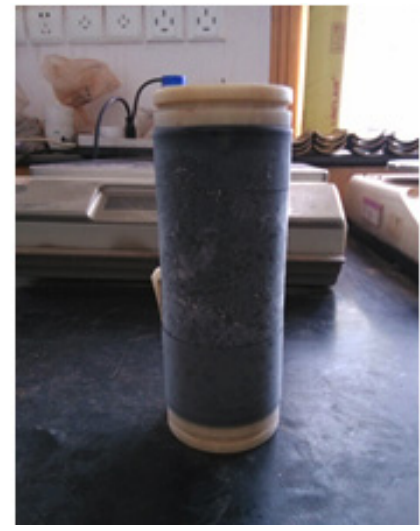

b. Prepared frozen soil sample

Fig. (1). MTS-810 material testing machine and prepared frozen soil sample.

\subsection{Test Conditions}

During the test, the samples are quickly installed in low temperature dynamic triaxial test machine and are put into the low temperature pressure chamber to consolidate for 5 $\mathrm{min}$. The loading procedure of every sample is divided into 4 steps: the consolidation process, the axial static load application process, the axial static load keeping process and the axial dynamic load application process. Among them, the axial dynamic load is a pressure - pressure sine wave under classified cyclic loadings, and vibrates 12 circles in every cyclic loading, which is shown in (Fig. 2). The class for the loading is over 12 . With the same dynamic load, all the test specimen are studied comparatively, and the result is shown in Table 2. The termination criterion is that the axial deformation reaches $20 \%$ and the controlled conditions in the test are shown in Table 3.
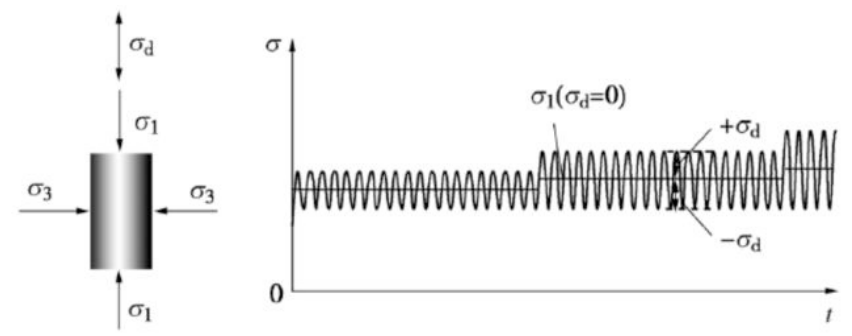

Fig. (2). Diagram of axial graded cyclic compressive stress loading. 
Table 1. Physical parameters table.

\begin{tabular}{|c|c|c|c|c|c|}
\hline Soil property & Liquid limit (\%) & Plastic limit (\%) & Plasticity index (\%) & Dry density (g/cm $\left.\mathbf{c m}^{\mathbf{3}}\right)$ & $\begin{array}{c}\text { The optimum water } \\
\text { content (\%) }\end{array}$ \\
\hline \hline Qinghai Tibet clay & 18.5 & 10.5 & 8 & 1.8 & 14.0 \\
\hline
\end{tabular}

Table 2. Dynamic load class of permafrost's dynamics parameters $\left(\sigma_{3}=0.3 \mathrm{MPa}\right)$.

\begin{tabular}{|c|c|c|c|c|c|c|c|c|c|c|}
\hline Load classes n & $\mathbf{1}$ & $\mathbf{2}$ & $\mathbf{3}$ & $\mathbf{4}$ & $\mathbf{5}$ & $\mathbf{6}$ & $\mathbf{7}$ & $\mathbf{8}$ & $\mathbf{9}$ & $\mathbf{\cdots}$ \\
\hline \hline$\sigma_{1 \mathrm{~min}} / \mathrm{MPa}$ & 0.30 & 0.30 & 0.30 & 0.30 & 0.30 & 0.30 & 0.30 & 0.30 & 0.30 & 0.30 \\
\hline$\sigma_{1 \mathrm{max}} / \mathrm{MPa}$ & 0.60 & 0.90 & 1.20 & 1.50 & 1.80 & 2.10 & 2.40 & 2.70 & 3.00 & $0.3(\mathrm{n}+1)$ \\
\hline$\sigma_{\mathrm{d}} / \mathrm{MPa}$ & 0.15 & 0.30 & 0.45 & 0.60 & 0.75 & 0.90 & 1.05 & 1.20 & 1.35 & $0.15 \mathrm{n}$ \\
\hline
\end{tabular}

Table 3. The test conditions of permafrost kinetic parameters.

\begin{tabular}{|c|c|c|c|c|c|}
\hline Specimen number & Temperature $\left(\mathrm{T} /{ }^{\circ} \mathrm{C}\right)$ & $\begin{array}{c}\text { Confining pressure } \\
\left(\sigma_{3} / \mathbf{M P a}\right)\end{array}$ & $\begin{array}{c}\text { Moisture content } \\
(\%)\end{array}$ & Frequency $(\mathrm{Hz})$ & cycle index \\
\hline YTX01 & \multirow{3}{*}{-5} & 0.3 & \multirow{7}{*}{14.5} & \multirow{10}{*}{2} & \multirow{13}{*}{12} \\
\hline YTX02 & & 0.6 & & & \\
\hline YTX03 & & 0.9 & & & \\
\hline YTX05 & -3 & \multirow{10}{*}{0.3} & & & \\
\hline YTX06 & -9 & & & & \\
\hline YTX07 & -7 & & & & \\
\hline YTX08 & -11 & & & & \\
\hline YTX12 & \multirow{6}{*}{-5} & & Saturation & & \\
\hline YTX13 & & & 15.5 & & \\
\hline YTX14 & & & 12.5 & & \\
\hline YTX15 & & & \multirow{3}{*}{14.5} & 0.5 & \\
\hline YTX16 & & & & 1 & \\
\hline YTX17 & & & & 4 & \\
\hline
\end{tabular}

\section{RESULTS ANALYSIS AND CONCLUSION}

The dynamics parameters of permafrost often include dynamic elastic modulus, dynamic shear modulus and damping ratio. And in this paper, the dynamic shear modulus and damping ratio of frozen silty clay are mainly analyzed and discussed.

\subsection{Dynamic Shear Modulus of Frozen Soil}

The dynamic stress-strain relationship of subgrade soil under traffic load can be shown by equivalent linear model. The dynamic shear modulus and the damping ratio are two important parameters to measure the dynamic performance. The hysteretic curve of frozen soil under dynamic load is as (Fig. 3) shows.

The dynamic shear stress amplitude $\tau_{d}$ and dynamic shear strain amplitude $\gamma_{d}$ of every loading class are calculated through the following formulas. Every time the dynamic load circulates, a delayed curve, as (Fig. 3) shows, will be formed. When drawing the hysteresis loop, Hardin suggested to use the hyperbolic curve, as formula (1) shows, to fit the relation curve (backbone curve) of the soil's shear stress amplitude and shear strain amplitude. 


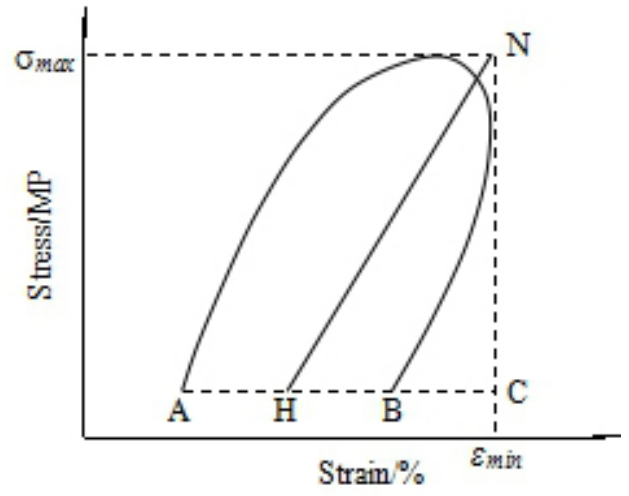

(a)

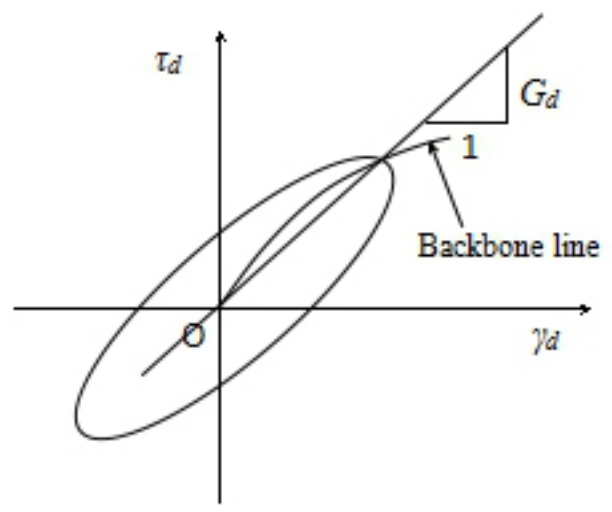

(b)

Fig. (3). Determination of dynamic shear modulus and damping ratio.

$$
\tau_{d}=\frac{\gamma_{d}}{a+b \gamma_{d}}
$$

And the dynamic shear modulus $G_{d}$ is defined as the average slope of the delayed curve and the dynamic modulus of elasticity $E_{d}$ is calculated in terms of the dynamic stress $\sigma_{d}$ and dynamic strain $\varepsilon_{d}$ that are shown in the (Fig. 3).

$$
\begin{aligned}
& \gamma_{d}=\varepsilon_{d}(1+\mu) \\
& \tau_{d}=\frac{\sigma_{d}}{2} \\
& G_{d}=\frac{\tau_{d}}{\gamma_{d}} \\
& G_{d}=\frac{E_{d}}{2(1+\mu)} \\
& E_{d}=\frac{\sigma_{d}}{\varepsilon_{d}}
\end{aligned}
$$

Through combining formula 5 and formula 6 , formula 7 can be concluded.

$$
G_{d}=\frac{\sigma_{d}}{2 \varepsilon_{d}(1+\mu)}
$$

In the formula: $\varepsilon_{d}-$ Axial dynamic strain amplitude;
$\sigma_{d}$-Axial dynamic stress amplitude;

$\mu$-Dynamic Poisson's ratio [20, 21].

Under different temperatures, confining pressures and water contents etc., the relation curves of dynamic shear stress amplitude, dynamic shear strain amplitude and dynamic shear modulus of the frozen soil can be drawn by the above-mentioned formulas. The curves are shown in (Fig. 4-11). As can be seen from the figures, the dynamic shear strain amplitude is from 0.0001 to 0.007 , the dynamic shear stress amplitude from $0.1 \mathrm{MPa}$ to $2.1 \mathrm{MPa}$, and dynamic shear modulus from $152 \mathrm{MPa}$ to $804 \mathrm{MPa}$. As the dynamic shear strain amplitude increases, the dynamic shear stress amplitude also rises. The relation curve can be divided into initial linear period, medium-term nonlinear period, and later approximately linear period. The influence that dynamic shear modulus has on dynamic shear strain amplitude is quite complicated and should be analyzed through different factors.

\subsubsection{Temperature}

When the confining pressure is $0.3 \mathrm{MPa}$, moisture content $14.5 \%$ and frequency $2 \mathrm{~Hz}$, under five different negative temperatures, the backbone curves of frozen soil are as (Fig. 4) shows. As can be seen from the figure, temperature plays a significant role in the backbone curve. Under the same dynamic shear strain amplitude, the dynamic shear stress amplitude increases as the temperature falls from $-3^{\circ} \mathrm{C}$ to -11 ${ }^{\circ} \mathrm{C}$, with the final value reaching $2.03 \mathrm{MPa}$ from $0.87 \mathrm{MPa}$.

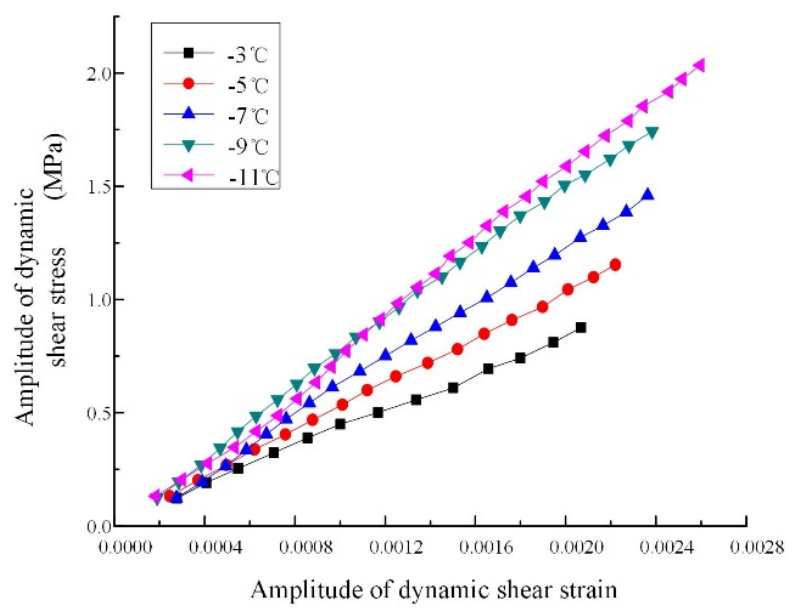

Fig. (4). Backbone curves of frozen soil under different temperature conditions.

Under five different temperatures, the changing curves of the dynamic shear modulus and the dynamic shear strain amplitude are presented in (Fig. 5). As shown in the figure, when under the five different temperatures, and with the increase of the dynamic shear strain amplitude, the dynamic shear modulus first rises, then levels off and then slows down in the end. As the temperature falls from $-3{ }^{\circ} \mathrm{C}$ to $-11{ }^{\circ} \mathrm{C}$ , the dynamic shear modulus increases significantly with the final value reaching from $423.5 \mathrm{MPa}$ to $782.2 \mathrm{MPa}$. This is because with the same water content, lower temperature will cause more free water to crystallize, resulting in stronger binding power between the soil grains and crystals. There- 
fore, the soil becomes more rigid, resulting in the increase in the dynamic shear modulus.

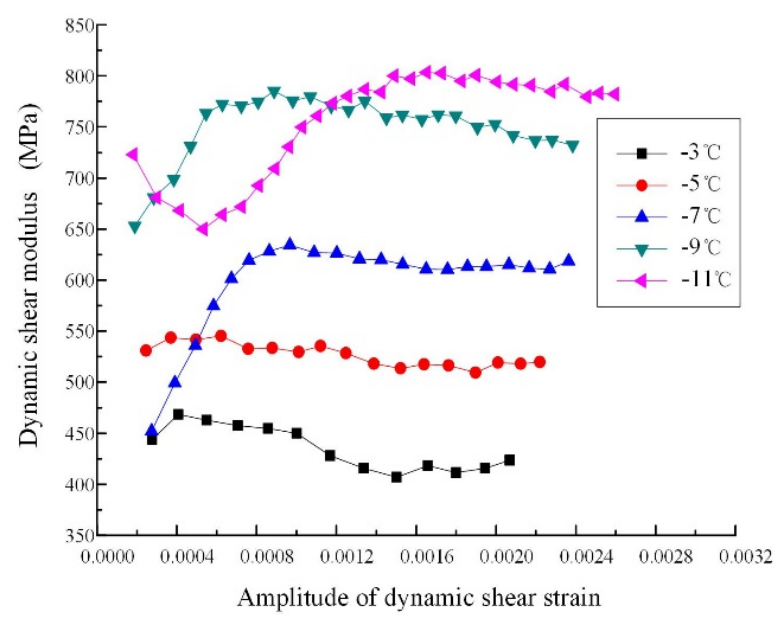

Fig. (5). Relationship between dynamic shear modulus and dynamic shear strain amplitude under different temperature conditions.

\subsubsection{Confining Pressure}

When the temperature is $-5^{\circ} \mathrm{C}$, moisture content $14.5 \%$ and frequency $2 \mathrm{~Hz}$, under four different confining pressures, the backbone curves of frozen soil are as (Fig. 6) shows. As is known from the figure, the confining pressure doesn't have a significant influence on the curve. Under the same dynamic shear strain amplitude, as the confining pressure increases from $0.3 \mathrm{MPa}$ to $1.2 \mathrm{MPa}$, the dynamic shear stress amplitude keeps rising. However, when the confining pressure is between $0.6 \mathrm{MPa}$ and $1.2 \mathrm{MPa}$, the dynamic shear stress amplitudes are very close to each other.

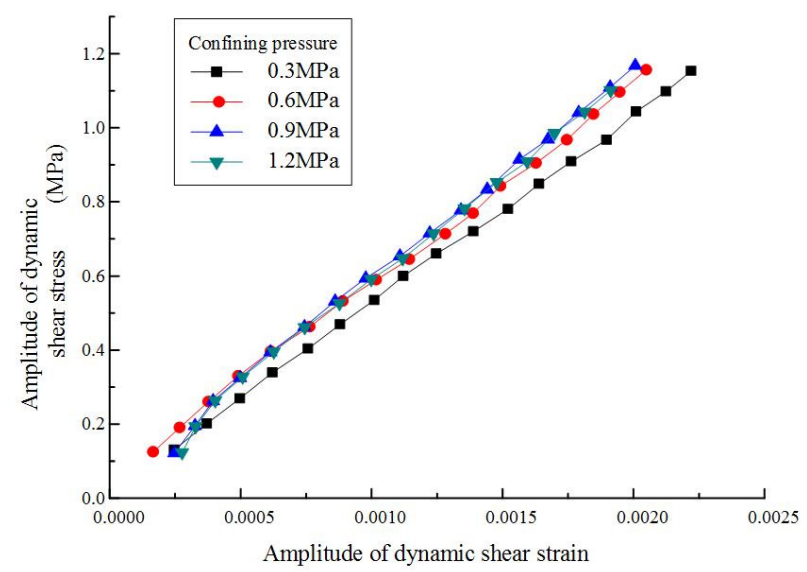

Fig. (6). backbone curves of frozen soil under different confining pressures.

Under four different confining pressures, the changing curves of the dynamic shear modulus and dynamic shear strain amplitude are presented in (Fig. 7). As is shown in the figure, the confining pressure plays a significant role on the dynamic shear modulus. When the confining pressure is between $0.3 \mathrm{MPa}$ and $1.2 \mathrm{MPa}$, the dynamic shear modulus will increase with increasing confining pressure. However, when the confining pressure is large enough, this kind of influence will weaken. With the increase in the confining pressure, the soil grains will be dislocated by force with decreasing soil porosity, resulting in the strengthening of the soil structure and the increase in dynamic shear modulus. But that doesn't mean this direct proportion will last all the time. After the soil is consolidated to a very close extent, the increase of the strength will not be that obvious.

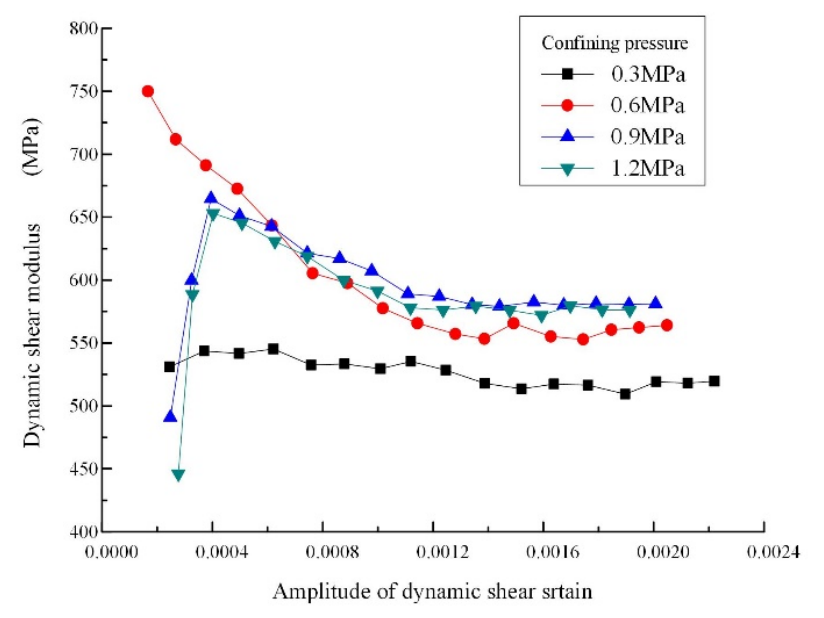

Fig. (7). Relationship between dynamic shear modulus and dynamic shear strain amplitude under different confining pressures.

\subsubsection{Frequency}

When the temperature is $-5^{\circ} \mathrm{C}$, confining pressure $0.3 \mathrm{MPa}$, and moisture content $14.5 \%$, under four different frequencies, the backbone curves of frozen soil are shown in (Fig. 8). Under the same dynamic shear strain amplitude, the dynamic shear stress amplitude increases with increasing frequency. However, when the frequency is $1 \mathrm{~Hz}$, it will be much smaller than those under other frequencies, and its dynamic shear strain amplitude varies widely.

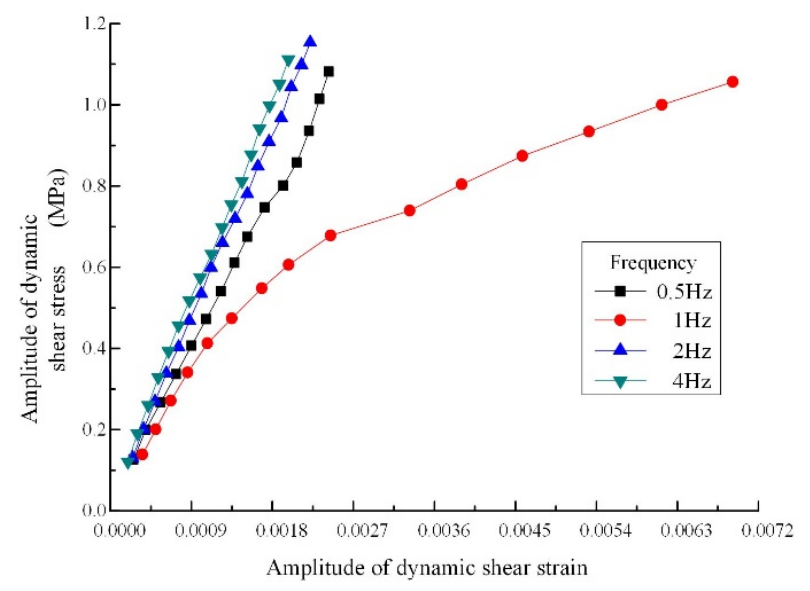

Fig. (8). Backbone curves of frozen soil under different frequency conditions.

Under four different frequencies, the changing curves of the dynamic shear modulus and the dynamic shear strain amplitude are as (Fig. 9) shows. It is presented in the figure that when the frequency is $0.5 \mathrm{~Hz}, 2 \mathrm{~Hz}$ and $4 \mathrm{~Hz}$ respectively and under the same dynamic shear strain amplitude, the dy- 
namic shear modulus will rise as the frequency rises. But when the frequency is $1 \mathrm{~Hz}$, it will be smaller than those under other frequencies. Under the four frequencies, as dynamic shear strain amplitude increases, the dynamic shear modulus first rises and then drops. And when the frequency is $1 \mathrm{~Hz}$, the dynamic shear modulus decreases to a larger extent than those under other frequencies. Loading frequency can reflect the loading rate, which will get higher with increasing loading frequency, meanwhile, the time for the plastic flow of the grains and ice in the soil will be shortened. The increase in the soil's rigidity will weaken its deformability, thus its dynamic shear modulus will increase. Otherwise, the loading rate will slow down with decreasing loading frequency, then the deformability of the soil will be strengthened and the dynamic shear modulus will decrease. If the frequency is $1 \mathrm{~Hz}$, it might have something to do with the natural vibration frequency of the soil itself.

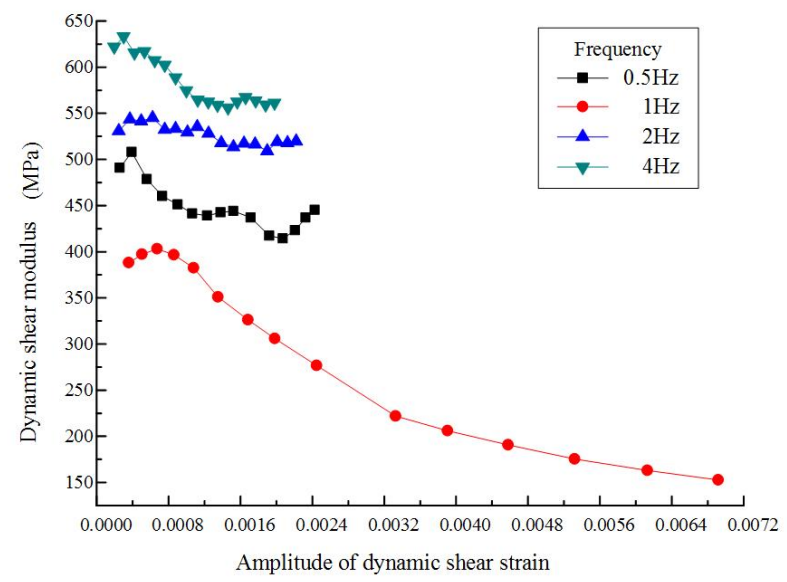

Fig. (9). Relationship between dynamic shear modulus and dynamic shear strain amplitude under different frequency conditions.

\subsubsection{Moisture Content}

To control the moisture content is a hard task when preparing the samples. In this test, two methods are adopted to prepare samples with different moisture contents. The first one is to determine the contents of soil and contents of water respectively according to the required moisture content, and then to mix the two materials together. The saturated sample is made from the sample with $14.5 \%$ water content, by vacuum pumping and water filling, and the corresponding test results are shown in (Fig. 10a) and (Fig. 11a). The other one is to prepare the samples with $14.5 \%$ water content and through drying or humidifying them, other samples with different water contents can be prepared. The saturated sample is made from the sample with $11 \%$ water content, also by vacuum pumping and water filling. In this way, the soil grains are equally distributed, and the results are shown in (Fig. 10b) and (Fig. 11b).

When the temperature is $-5^{\circ} \mathrm{C}$, frequency $2 \mathrm{~Hz}$, and confining pressure $0.3 \mathrm{MPa}$, with four different water contents that are made by the two preparation methods above, the backbone curves of the frozen soil are shown in (Fig. 10a) and (Fig. 10b). As can be seen from the figures, under the same dynamic shear strain amplitude, the dynamic shear stress amplitude increases as the water content gets higher.
When the water contents are $14.5 \%$ and $15.5 \%$ respectively, the two curves are very close to each other since there is little difference. While in the saturated condition, under the same dynamic shear strain amplitude, the dynamic shear stress amplitude from the first preparation method will be larger than that from the second one, and so as the final dynamic shear stress amplitude.

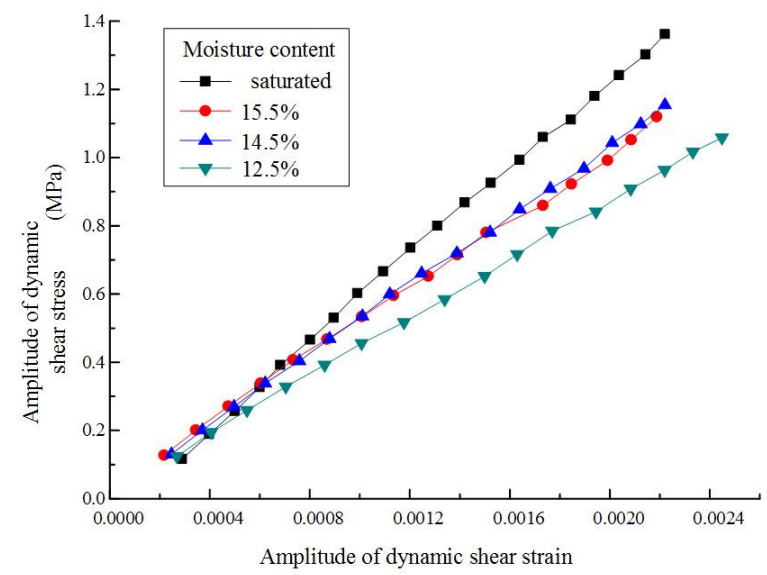

(a)

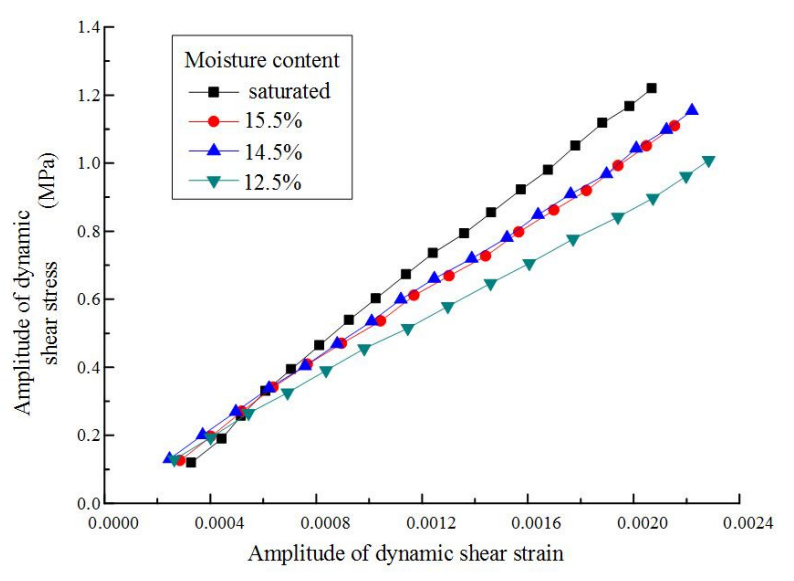

(b)

Fig. (10). Backbone curves of frozen soil under different moisture contents.

Under four different moisture contents, the relation curves of dynamic shear modulus and dynamic shear strain amplitude of the frozen soil samples made through the two different preparation methods are shown in (Fig. 11a) and (Fig. 11b). According to the figures, under the same dynamic shear strain amplitude, the dynamic shear modulus will rise with increasing water content. The main reason is that as the water content gets higher, more free water in the soil body will crystallize under the same minus temperature. These crystals will refill the soil skeleton, contributing to increasing acting forces among the soil grains. In this way, the soil is strengthened and its dynamic shear modulus increases. However, the dynamic shear modulus with $15.5 \%$ water content is smaller than that with $14.5 \%$ water content. Because in general, the number of crystals in the soil body will increase with higher water content, and so as the soil's rigidity 
and its dynamic shear modulus. But when the water contents are almost the same, their influence on dynamic shear modulus will not be that remarkable. Because the curves drawn from the two different preparation methods are quite similar to each other. When in saturated condition and under the same dynamic shear strain amplitude, the dynamic shear modulus in (Fig. 11a) is larger than that in (Fig. 11b). The reason lies in that in the first method, the soil grains are relatively larger, and so as the small openings among the grains, meanwhile, large amounts of crystals among the grains are concentrated, resulting in the increase of the soil sample's rigidity. Therefore, its dynamic shear modulus is also larger.

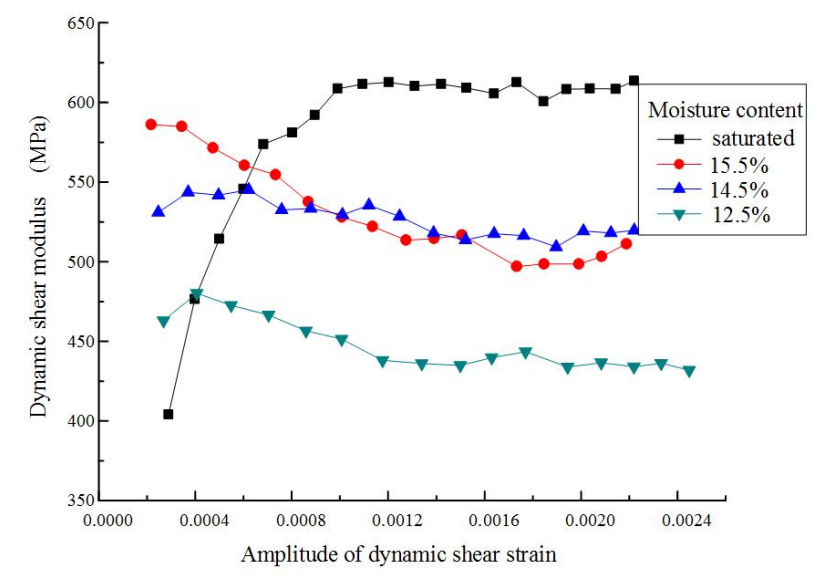

(a)

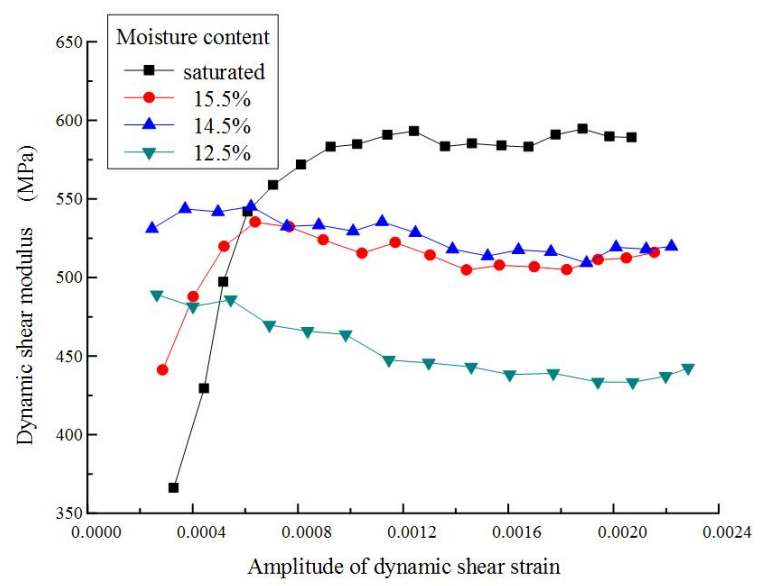

(b)

Fig. (11). Relationship between dynamic shear modulus and dynamic shear strain amplitude with different moisture contents.

\subsection{The Damping Ratio of Frozen Soil}

The damping ratio can be calculated by formula (4), among which $A_{L}$ means the area of dynamic shear stressdynamic shear strain hysteresis loop, and $\mathrm{A}_{\mathrm{T}}$ means the triangle area formed through the lines connecting the central point of hysteresis loop and the maximum point of shear stress and strain values. The formula is as follow [22]:

$$
\mu=\frac{A_{L}}{4 \pi A_{L}}
$$

In equivalent linearization model, the damping ratio is the function of dynamic shear strain amplitude. Through calculating the data from the test, the relation curves of the damping ratio and dynamic shear strain amplitude under different influencing factors can be drawn as (Fig. 12-15) show. As presented in the figures, the relationship between the damping ratio and various factors is quite complicated-when the damping ratio is between 0.1 and 0.55 , as the dynamic shear strain amplitude increases, the damping ratio of frozen soil, in general, first decreases and then increases.

\subsubsection{Temperature}

When the confining pressure is $0.3 \mathrm{Mpa}$, the moisture content $14.5 \%$ and the frequency $2 \mathrm{~Hz}$, under five different temperatures, the relation curves of the damping ratio and dynamic shear strain amplitude are presented in (Fig. 12). According to the figure, with the increase of the dynamic shear strain amplitude, the damping ratio first decreases and then increases significantly, and in the middle phase, the increase becomes slow. With the same dynamic shear strain amplitude, as the temperature gets lower, the damping ratio of frozen soil decreases dramatically, the same as the maximum damping ratio. This is because as the temperature drops, the unfrozen-water content in frozen soil also gets lower, causing bigger bite force among the soil grains and the increase in the soil's strength and rigidity. At the same time, the deformability of the frozen soil is lessened, leading to even lower energy consumption. Therefore, the damping ratio decreases dramatically.

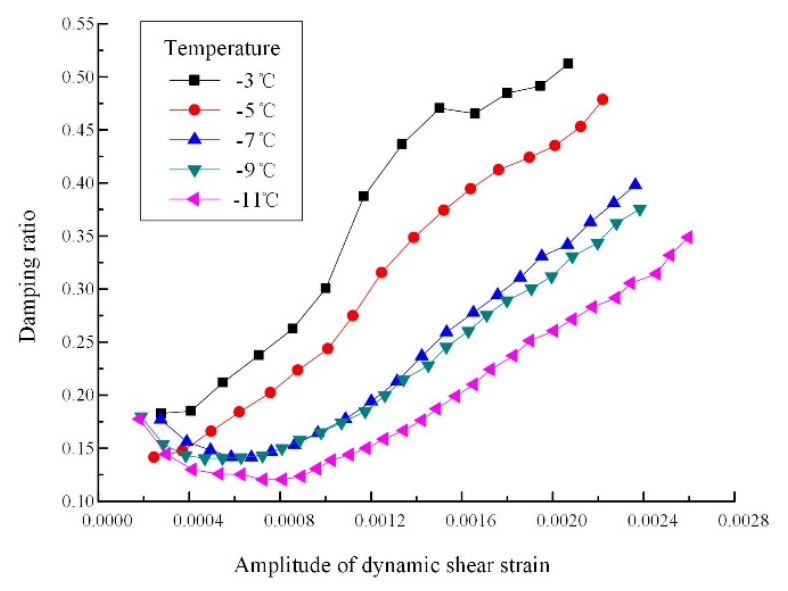

Fig. (12). Relationship between damping ratio and dynamic shear strain amplitude under different temperatures.

\subsubsection{Confining Pressure}

When the temperature is $-5^{\circ} \mathrm{C}$, the moisture content $14.5 \%$ and the frequency $2 \mathrm{~Hz}$, under four different confining pressures, the relation curves of the damping ratio and dynamic shear strain amplitude are shown in (Fig. 13). It can be seen from the figure that as the dynamic shear strain amplitude increases, the damping ratio first decreases and then increases markedly and finally levels off. With the same dynamic shear strain amplitude, the damping ratio of frozen soil is enhanced, but not that dramatically, along with the increase of the confining pressure. When the confining pressure is between $0.6 \mathrm{Mpa}$ and $1.2 \mathrm{Mpa}$, its influence is not that 
remarkable. The increasing confining pressure can gradually melt the ice crystals in the frozen soil, resulting in higher unfrozen-water content, thus, the deformability of the frozen soil is strengthened, causing more energy consumption. Therefore, the damping ratio increases.

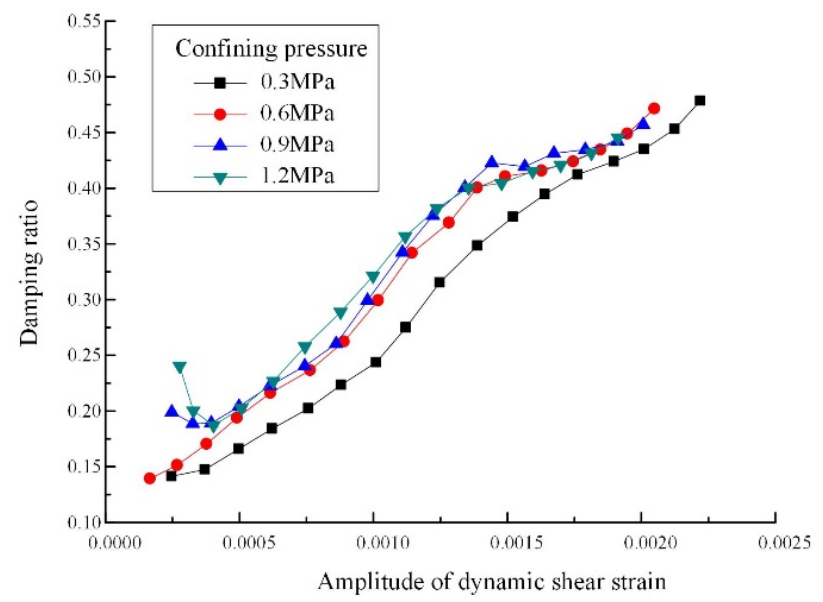

Fig. (13). Relationship between damping ratio and dynamic shear strain amplitude under different confining pressures.

\subsubsection{Moisture Content}

When the temperature is $-5^{\circ} \mathrm{C}$, the confining pressure $0.3 \mathrm{MPa}$ and the frequency $2 \mathrm{~Hz}$, under the condition of four different moisture contents and by the two samplepreparation methods above, the relation curves of the damping ratio and dynamic shear strain amplitude are as Fig. (14a) and (Fig. 14b) show. According to the figures, the relationship between the damping ratio and the moisture content is quite complicated and the distinction of the relation curves got from the two different preparation methods is quite remarkable. In (Fig. 14b), the damping ratios under different moisture contents are relatively close to each other; the curves representing $14.5 \%$ and $15.5 \%$ moisture content respectively are very close to each other since their moisture contents differ little; but when the moisture content is $12.5 \%$, the final damping ratios in the two figures are quite different from those under other moisture contents. If the soil is saturated, the first preparation method is usually a good choice and when the dynamic shear strain amplitudes are the same, the damping ratio of the frozen soil will be smaller than that from the second preparation method. The reason lies in that the soil grains in the first method are relatively bigger, and the small openings among grains are much larger as well as there are more crystals which are relatively concentrated among the grains. Thus, the soil sample is more rigid, resulting in less deformability and less energy consumption. As a result, the damping ratio is smaller than that of the second method.

\subsubsection{Frequency}

When the temperature is $-5^{\circ} \mathrm{C}$, the confining pressure $0.3 \mathrm{MPa}$ and the moisture content $14.5 \%$, under four different frequencies, the relation curves of the damping ratio and dynamic shear strain amplitude is as (Fig. 15) shows.

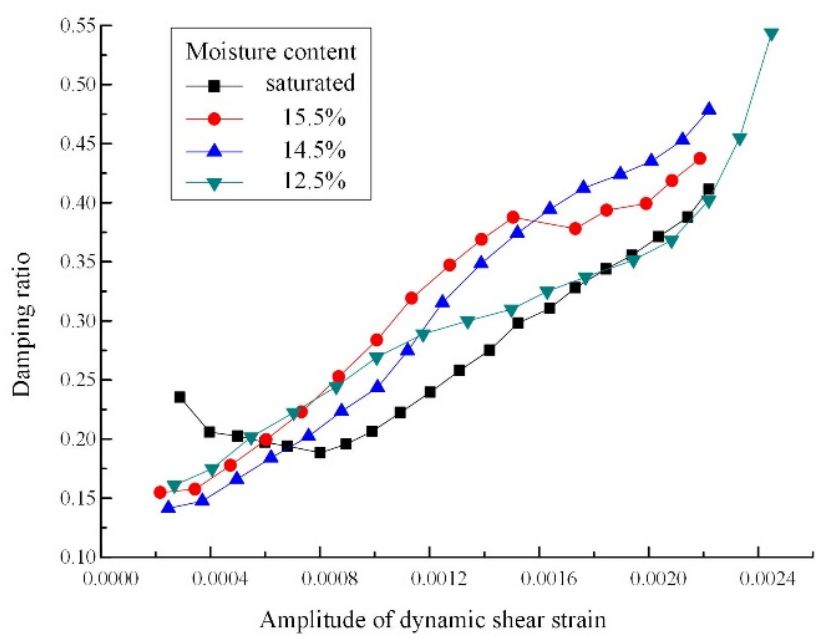

(a)

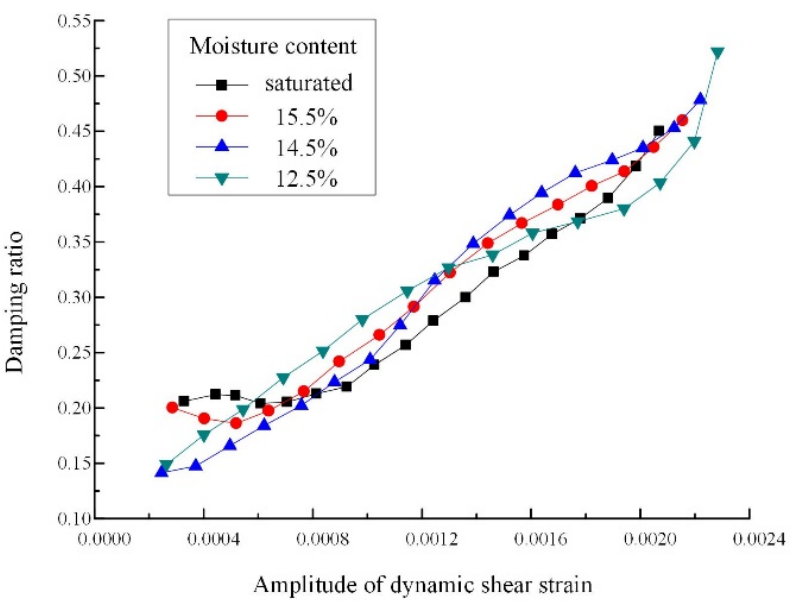

(b)

Fig. (14). Relationship between damping ratio and dynamic shear strain amplitude with different moisture contents.

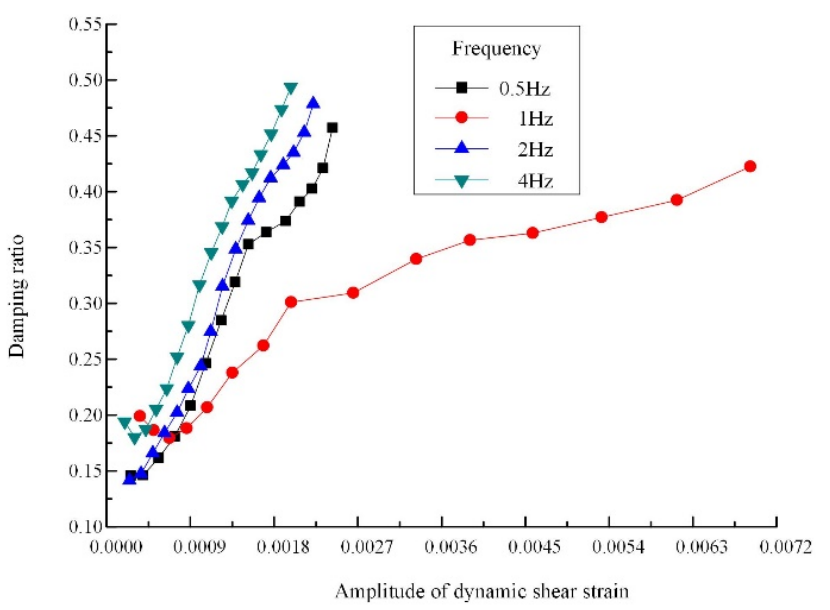

Fig. (15). Relationship between damping ratio and dynamic shear strain amplitude under different frequencies. 
It can be concluded from (Fig. 15) that with the increase of dynamic shear strain amplitude, the damping ratio first decreases and then increases. And when the frequency is $1 \mathrm{~Hz}$, the damping ratio is smaller than those under other frequencies. The reason may be that the loading frequency then is close to the soil's natural vibration frequency.

\section{CONCLUSION}

Based on the experiments and dynamics performance analysis towards the frozen silty clay in Amdo test section of Qinghai-Tibet Plateau. The followings can be concluded:

(1) Under different factors like temperature, confining pressure, moisture content and frequency, the dynamic shear strain amplitude of the frozen silty clay is from 0.0001 to 0.007 ; the dynamic shear stress amplitude is from $0.1 \mathrm{MPa}$ to $2.1 \mathrm{MPa}$; while the dynamic shear modulus is from $152 \mathrm{MPa}$ to $804 \mathrm{MPa}$ and the damping ratio, 0.1 to 0.55 . The dynamic shear stress amplitude increases along with the rise of the dynamic shear strain amplitude, but the relationship between the dynamic shear modulus and the dynamic shear strain amplitude is quite complex--the damping ratio first decreases and then increases later.

(2) Temperature plays a significant role in the backbone curve of frozen soil. When the temperature falls from $-3^{\circ} \mathrm{C}$ to $-11^{\circ} \mathrm{C}$, the final dynamic shear stress amplitude will increase from $0.87 \mathrm{MPa}$ to $2.03 \mathrm{MPa}$. As the temperature drops, the dynamic shear modulus is enhanced markedly, with the final value reaching $782.2 \mathrm{MPa}$ from $423.5 \mathrm{MPa}$. As the temperature falls down, the binding power between the soil grains and crystals will be stronger and the dynamic shear modulus will increase. Under the same dynamic shear strain amplitude, the frozen soil's damping ratio will decrease remarkably along with the drop in the temperature.

(3) The influence of the confining pressure on backbone curve is not quite remarkable. When the confining pressure increases from $0.3 \mathrm{MPa}$ to $1.2 \mathrm{MPa}$, under the same dynamic shear strain amplitude, the dynamic shear stress amplitude will keep rising. The confining pressure is a more critical factor on the dynamic shear modulus. However, when the confining pressure is large enough, its influence will eventually weaken. As the confining pressure rises, the grains will be dislocated with force, making the soil more rigid and the dynamic shear modulus to increase. Under the same dynamic shear strain amplitude, the damping ratio increases with rising confining pressure, even though the increase may not be that obvious.

(4) Under the same dynamic shear strain amplitude, the dynamic shear modulus will rise with increasing water content. When under saturated condition, the soil grains are relatively large, and so as the small openings among the grains, meanwhile, the crystals among the grains are concentrated together, causing the increase in the soil sample's rigidity. Therefore, its dynamic shear modulus is larger and the damping ratio is relatively smaller.

\section{CONFLICT OF INTEREST}

The authors confirm that this article content has no conflict of interest.

\section{ACKNOWLEDGEMENTS}

This work is supported by the national natural science fund (51479174), The 2015 science and technology innovation fund for graduates of Yantai University (01061).

\section{REFERENCES}

[1] Y. Zhou, D. Guo, and G. Qiu, China Permafrost, Science Press, Beijing, 2000, pp. 157-360.

[2] G. Cheng, Z. Sun, and F. Niu, "Application of the roadbed cooling approach in qinghai-tibet railway engineering", Journal of Cold Regions Science and Technology, vol. 53, pp. 241-258, 2008.

[3] H. A. Li, Mechanics of Frozen Ground, Science Press, Beijing, 1983, pp. 108-151.

[4] T. Chaichanavong, "Dynamic Properties of Ice and Frozen Clay under Cyclic Triaxial Loading Conditions", Dept. of Civil and Sanitary Engineering. Michigan State University, East Lansing, 1976.

[5] J. C. Li, G. Y. Baladi, and O. B. Andersland, "Cyclic triaxial tests on frozen sand", Journal of Engineering Geology, vol. 13, no. 4, pp. 233-246, 1979

[6] J. M. Ting, R. T. Martin, and C. C. Ladd, "Mechanisms of strength for frozen sand", Journal of Geotechnical Engineering, vol. 109, no. 10, pp. 1286-1302, 1983.

[7] M.Y. Kim, and H.T. Yun, "Exact dynamic and static element stiffness matrices of no symmetric thin-walled beam-columns", Journal of Computers and Structures, vol. 81, no. 14, pp. 1425-1448, 2003.

[8] Y. Zhu, P. He, J. Zhang, and J. Wang, "Effect of confine pressure on creep behavior of frozen silt under dynamic loading", Journal of Glaciology and Geocryology, vol. 17, pp. 20-25, 1995.

[9] X. Xu, C. Zhong, and Y. Chen, "Research on dynamic characters of frozen soil and determination of its parameters", Chinese Journal of Geotechnical Engineering, vol. 20, no. 5, pp. 77-81, 1998.

[10] X. Xu, and C. Zhong, "The determination of dynamic elastic modulus and dynamic Poisson's ratio of frozen soil", Journal of Harbin University of C. E \& Archiecture, vol. 30, no. 4, pp. 23-29, 1997.

[11] S. Zhao, and Y. Zhu, "Testing study on dynamic mechanics parameters of frozen soil", Chinese Journal of Rock Mechanics and Engineering, vol. 22, no. 2, pp. 3677-3681, 2003.

[12] Y. Shi, P. He, and X. Bian, "Experimental study of high temperature frozen soil dynamic parameters of qinghai-tibet railway", Subgrade Engineering, vol. 5, 2006, pp. 93-95.

[13] Z. Zhu, X. Ling, S. Chen, Z. Feng, L. Wangb, Z. Wangb, and Z. Zou, "Experimental investigation on the train-induced subsidence prediction model of Beiluhe permafrost subgrade along the Qinghai-Tibet Railway in China", Cold Regions Science and Technology, vol. 62, no. 1, pp. 67-75, 2010.

[14] Z. Zhu, X. Ling, Z. Wang, Q. Lud, S. Chena, Z. Zoub, and Z. Guo, "Experimental investigation on the dynamic behavior of frozen clay", Cold Regions Science and Technology, vol. 69, no. 1, pp. 9197, 2011.

[15] Z. Zhu, X. Ling, S. Chen, Z. Feng, Z. Wang, L. Wang, and Z. Zou "Analysis of dynamic compression stress induced by passing trains in permafrost subgrade along qinghai-tibet railway", Cold Regions Science and Technology, vol. 65, no. 1, pp. 465-473, 2011.

[16] P. Lv, J. Liu, and Y. Cui, "A study of dynamic shear strength of frozen soil-concrete contact interface", Rock and Soil Mechanics, vol. 34, pp. 180-183, 2013.

[17] X. Xu, Y. Lai, F. Liu, and X. Chang, "A study of mechanical test methods of frozen soil", Journal of Glaciology and Geocryology, vol. 33, no. 5, pp. 1132-1138, 2011.

[18] The Ministry of Water Resources of the People's Republic of China, Standard for Soil Test Method GB/T50123-1999, China Planning Press, Beijing, 1999, pp. 83-146.

[19] Machinery Industry Ministry of the people's Republic of China "Code for Measurement Method of Dynamic Properties Subsoil GB/T50269-1997," China Standard Press, Beijing, 1998, pp. 4056. 
[20] B. O. Hardin, and V. E. Drnevich, "Shear modulus and dam ping in soils design equations and curves", Journal of Soil Mechanics and Foundation, ASCE, vol. 98, no. SM7, pp. 603-624, 1972.

[21] K. Zhang, and J. Xie, Soil Dynamics, Seismological Press, Beijing, 1989, pp. 25-28.
[22] F. Shi, J. Liu, and J. Fang, "Subgrade dynamic stress test on highway in seasonal frozen soil area", China Journal of Highway and Transport, vol. 26, no. 5, pp. 15-20, 2013.

Received: May 26, 2015

Revised: July 14, 2015

Accepted: August 10,2015

(C) Bin et al.; Licensee Bentham Open.

This is an open access article licensed under the terms of the (https://creativecommons.org/licenses/by/4.0/legalcode), which permits unrestricted, noncommercial use, distribution and reproduction in any medium, provided the work is properly cited. 